\title{
Correction \\ Correction: Răzvan et al. Selective Laser Sintering of PA 2200 for Hip Implant Applications: Finite Element Analysis, Process Optimization, Morphological and Mechanical Characterization. Materials 2021, 14, 4240
}

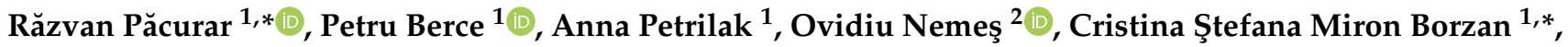 \\ Marta Harničárová ${ }^{3,4}$ and Ancuţa Păcurar ${ }^{1, *}$ \\ 1 Department of Manufacturing Engineering, Faculty of Industrial Engineering, \\ Robotics, Management and Production Management, Technical University of Cluj-Napoca, \\ B-dul Muncii 103-105, 400641 Cluj-Napoca, Romania; petru.berce@tcm.utcluj.ro (P.B.); \\ anna_petrilak@yahoo.com (A.P.) \\ 2 Department of Environmental Engineering and Sustainable Development Entrepreneurship, \\ Faculty of Materials and Environmental Engineering, Technical University of Cluj-Napoca, \\ B-dul Muncii 103-105, 400641 Cluj-Napoca, Romania; ovidiu.nemes@imadd.utcluj.ro \\ 3 Department of Electrical Engineering, Automation and Informatics, Faculty of Engineering, \\ Slovak University of Agriculture in Nitra, Tr. A. Hlinku 2, 94976 Nitra, Slovakia; \\ marta.harnicarova@uniag.sk \\ 4 Department of Mechanical Engineering, Faculty of Technology, Institute of Technology and Business in České \\ Budějovice, Okružní 10, 37001 České Budějovice, Czech Republic \\ * Correspondence: razvan.pacurar@tcm.utcluj.ro (R.P.); cristina.borzan@tcm.utcluj.ro (C.S.M.B.); \\ ancuta.costea@tcm.utcluj.ro (A.P.)
}

check for

updates

Citation: Păcurar, R.; Berce, P.;

Petrilak, A.; Nemeş, O.; Borzan,

C.Ş.M.; Harničárová, M.; Păcurar, A

Correction: Răzvan et al. Selective Laser Sintering of PA 2200 for Hip Implant Applications: Finite Element Analysis, Process Optimization,

Morphological and Mechanical Characterization. Materials 2021, 14, 4240. Materials 2022, 15, 132. https:// doi.org/10.3390/ma15010132

Received: 22 September 2021 Accepted: 25 November 2021 Published: 24 December 2021

Publisher's Note: MDPI stays neutral with regard to jurisdictional claims in published maps and institutional affiliations.

Copyright: (C) 2021 by the authors. Licensee MDPI, Basel, Switzerland. This article is an open access article distributed under the terms and conditions of the Creative Commons Attribution (CC BY) license (https:// creativecommons.org/licenses/by/ $4.0 /)$.
The authors wish to make the following correction to their paper [1]

Incorrect Title

There is an error in the title. The correct title of the article is "Selective Laser Sintering of PA 2200 for Hip Implant Applications: Finite Element Analysis, Process Optimization, Morphological and Mechanical Characterization". We apologize for this error and state that the scientific conclusions are unaffected. The original article has been updated.

\section{Reference}

1. Păcurar, R.; Berce, P.; Petrilak, A.; Nemeş, O.; Borzan, C.Ş.M.; Harničárová, M.; Păcurar, A. Selective Laser Sintering of PA 2200 for Hip Implant Applications: Finite Element Analysis, Process Optimization, Morphological and Mechanical Characterization. Materials 2021, 14, 4240. [CrossRef] 